\title{
A Linguagem de Programação Aliada ao Desenho na Criação de Jogos Digitais como Instrumento de Arquitetura Patrimonial
}

\author{
The Programming Language Allied with Drawing on the Creation of Digital Games as a Tool of the \\ Architectural Heritage
}

\author{
Érika Miwa Okushigue Ghisolfi \\ Instituto de Arquitetura e Urbanismo de São Carlos \\ Universidade de São Paulo, Brasil \\ erika.ghisolf@usp.br
}

\author{
Simone Helena Tanoue Vizioli \\ Instituto de Arquitetura e Urbanismo de São Carlos \\ Universidade de São Paulo, Brasil \\ simonehtv@sc.usp.br
}

\begin{abstract} the city of São Carlos, Brasil.

\section{Introdução}

A inclusão dos computadores no cotidiano possibilita novas experiências, ampliando as fronteiras do conhecimento humano. Neste contexto, os jogos digitais alcançaram grande popularidade, substituindo as tradicionais formas do brincar pela imersão no mundo digital. Diferentemente dos brinquedos, esses jogos não possuem materialidade sendo dependentes das imagens que os compõem para serem atrativos. Dessa forma, são responsáveis por gerar novas percepções através da exploração e interação do usuário com a interface digital. Nessa perspectiva, surgem questionamentos sobre seus efeitos no comportamento e aprendizado infantil e torna-se oportuno avaliar sua aplicabilidade na área de ensino, no contexto de divulgação da arquitetura patrimonial.
\end{abstract}

This research studies the use of digital games as a playful tool approach of knowledge in architecture heritage. We emphasize the potential of digital games as a teaching tool and the importance of digital drawing combined with programming language, the means by which the making of the games became possible. The models developed are based on the properties of historical and cultural interest in

Keywords: Digital games; Programming language; Digital drawing; Heritage education; Playfulness.
Paralelamente, a linguagem de programação e o desenho digital surgem como novas ferramentas de design, através das quais o conhecimento pode ser construído, reproduzido e disseminado. 0 desenho já demonstrou grande aplicabilidade no campo da arquitetura, desde os croquis à mão ao uso de tablets e ferramentas digitais. A linguagem de programação, contudo, não tem tido grande destaque entre os profissionais dessa área. Esse estudo pretende demonstrar que ela pode ser utilizada para ampliar o conhecimento e ensino da arquitetura e a compreensão do design, ao menos, através da confecção dos jogos em questão.

\section{Objetivos}

A presente pesquisa insere-se nas atividades desenvolvidas pelo Núcleo de Apoio à Pesquisa em Estudos de Linguagem da Arquitetura e da Cidade. Com a perspectiva de aliar as questões do município de São Carlos ao estudo da arquitetura e da cidade, o N.ELAC propôs a construção de três sistemas interativos: blocos lúdicos manipuláveis, dobraduras em papel e no caso específico dessa pesquisa, jogos eletrônicos.

Desenvolveram-se jogos digitais com o objetivo de estimular o conhecimento dos edifícios de valor histórico, artístico e cultural do município de São Carlos através de sua manipulação, aproximando-se, assim, da educação patrimonial. O público-alvo da pesquisa são alunos da rede pública de ensino, assim como a comunidade são carlense e seus visitantes.

Este trabalho propõe-se a ressaltar o potencial dos jogos digitais como uma ferramenta lúdica de construção e apreensão do conhecimento patrimonial. Para tanto, evidencia-se a importância do estudo de diversas áreas do conhecimento como a linguagem de programação e o desenho digital, meios pelos quais tornou-se possível a confecção dos jogos desenvolvidos.

\section{Métodos}

A pesquisa em questão foi composta por várias etapas. $\mathrm{Na}$ primeira etapa construiu-se um repertório teórico relacionado a atividade lúdica, a apreensão cognitiva da criança, a educação patrimonial, ao desenho digital, aos jogos eletrônicos e as formas e metodologias para sua confecção. A segunda etapa constou de experimentação prática e elaboração dos jogos digitais.

Para a criação dos jogos foram escolhidos três edifícios do Projeto Percursos desenvolvido pela Prefeitura Municipal de São Carlos em parceria com a Fundação Pró-Memória. Trata-se de uma 
cartilha acompanhada de um mapa da cidade que busca catalogar e divulgar as edificações de interesse histórico e arquitetônico da cidade de São Carlos. Os edifícios escolhidos possuíam características arquitetônicas e tipológicas distintas, sendo um imóvel da arquitetura moderna, um edifício com características do art déco e a Estação Ferroviária Local com fachada eclética.

Foram realizados desenhos de levantamento que permitiram a apreensão da forma e das principais características das construções. Os desenhos constituíram-se em importantes ferramentas de representação, comunicação, apropriação e formação do conhecimento.

Posteriormente, prosseguiu-se o estudo e a aprendizagem da linguagem de programação Processing, meio pelo qual ocorreu o processo de confecção dos jogos. Dois tipos de jogos foram propostos, quebra-cabeças e um mapa digital, os quais foram confeccionados a medida que a linguagem de programação era aprendida.

A terceira etapa ainda será executada, consistindo na usabilidade do jogo junto ao público-alvo e posterior avaliação dos resultados.

\section{Jogos Digitais Como Ferramentas do Ensino Patrimonial}

Roger Caillois (1990) coloca em evidência a importância dos jogos, pois as atividades lúdicas são os meios privilegiados nos quais a cultura de um povo e de uma sociedade pode manifestar-se. Através da obra de Caillois percebe-se que existe uma forte relação entre o jogo e a cultura. Os princípios básicos que regem os jogos identificados por Caillois como agôn (competição), alea (sorte), mimicry (simulacro) e inlix (vertigem) estão na base das instituições sociais e mantiveram-se presentes nas sociedades ao longo da história.

Apesar dos estudos do autor datarem da década de 1950, a partir de uma releitura atual pode-se pensá-lo no contexto dos jogos digitais. Segundo Caillois (1990), os jogos estruturados pelo agôn possuem como principal característica a competição. Este elemento está presente na maioria dos jogos, até mesmo nos jogos individuais, pois quando trata-se de uma atividade lúdica, o jogador prescinde a presença de espectadores imaginários que o estimulam a jogar. Dessa forma, demonstra-se que a atividade lúdica possui uma dimensão socializante, a qual permite a construção de um bem estar coletivo.

Os jogos eletrônicos, no entanto, são jogos individuais, responsáveis por substituir a interação entre as crianças pelas relações entre estas e o meio digital. Assim, Meira (2003) afirma que os jogos digitais não possuem a mesma dimensão simbólica das brincadeiras sociais. "Ao prescindir da presença do outro, a automatização que rege os jogos virtuais apresentaria efeitos de apagamento do tecido social que se construiria em presença." (p.78)

Contudo, como demonstra Santaella (2004) a dimensão do coletivo não está totalmente ausente da realidade virtual. "Todos os tipos de ambientes comunicacionais na rede se constituem em formas culturais e socializadoras do ciberespaço naquilo que vem sendo chamado de comunidades virtuais (Rheingold 1993), isto é, grupos de pessoas globalmente conectadas na base de interesses e afinidades, em lugar de conexões acidentais ou geográficas". (Rheingold apud Santaella, 2004, s/p.). Não se trata portanto de ausência de socialização mas do advento de novas formas dessa socialização, proporcionadas pela atual imersão no espaço virtual.

Nesta perspectiva, pode-se pensar, que os jogos digitais possuem resquícios de coletividade, os quais apresentam-se de uma forma diferente da tradicional através das comunidades virtuais ou da ideia da presença de um ser imaginário, muitas vezes prescindindo a presença de um ser humano real. Assim, manifestariam o agôn desta maneira, como também na competição contra si mesmo a qual o usuário está exposto, representada pelo desejo de autosuperação.

Os jogos digitais também podem se constituir em uma nova forma de brincadeira para a criança. "No caso dos games evidencia-se que a dimensão virtual revela a subtração da relação da criança com o processo de criação e ensaio próprios do brincar, já que os processos dos games estão previamente determinados. Por outro lado, podemos também pensar que estes jogos virtuais representam tentativas das crianças de "brincar com as imagens" que são hegemônicas na sociedade de consumo" (Meira, 1997,p 83).

Esta afirmação de Meira ressalta o quanto os jogos digitais são dependentes das imagens. Sem a dimensão da materialidade, os jogos digitais contam apenas com as imagens para fornecer experiência sensorial ao usuário. Para Vilém Flusser (1998) o tato nessas atividades se restringe ao toque das pontas dos dedos em contato com o teclado. As imagens técnicas são cada vez mais frequentes no cotidiano das pessoas, principalmente no das crianças que cresceram nesta realidade.

Flusser (1998) reforça a ideia presente em Meira de que as imagens e jogos digitais podem contribuir para a dispersão social. Essa dissolução da sociedade só é possível para o autor através da atuação das imagens sobre o indivíduo, as imagens o fascinam e divertem resultando na alienação social. Brougère, ao contrário, evidencia o potencial das imagens relacionadas aos jogos ao afirmar que "os videogames têm um papel cada vez mais importante, na junção do objeto de jogo com o espetáculo digital. Eles põe em imagens e em jogo os elementos da cultura." (Brougère, 2004, p. 332) 
É nessa perspectiva e através dos estudos de Caillois, que surge o entendimento de que os jogos podem, como elementos da cultura, ser por ela determinados e auxiliar em sua disseminação. Considera-se, portanto, que os jogos possam ser direcionados para a formação de uma consciência histórica que permita a preservação do patrimônio histórico ao aproximar-se da educação patrimonial. "A Educação Patrimonial é um instrumento de "alfabetização cultural" que possibilita ao indivíduo fazer a leitura do mundo que o rodeia, levando-o à compreensão do universo sociocultural e da trajetória histórico-temporal em que está inserido. (Horta, Grunberg \& Monteiro, 1999, p.6)

A inserção dos jogos digitais nos processos de aprendizagem pode impulsionar o interesse e a motivação dos alunos pelo conteúdo das aulas, por se tratar de uma atividade descontraída. "O uso dos jogos digitais nesse processo de aprendizagem desperta elementos cognitivos do aluno como atenção, percepção, aprendizagem, emoção, contribuindo para o desenvolvimento do aluno". (Costa, Prampero \& Figueiredo, 2009, p.2)

Autores como Albuquerque e Fialho (2010) também mantém opiniões positivas em apologia aos jogos. Ao mudar os hábitos das novas gerações "os jogos também tornariam as pessoas mais "inteligentes", ao popularizar formas de entretenimento que exigem raciocínios complexos e com grande exigência cognitiva." (Albuquerque \& Fialho, 2010, p.175). Portanto, jogos que incentivem as atividades de raciocínio, assim como jogos educativos são bem vistos entre os jogos digitais.

A interatividade também pode ser considerada como um fator positivo presente nos jogos eletrônicos, o que contribui para a adaptação à rapidez em que ocorrem as mudanças contemporâneas. A interatividade é o elemento que diferencia os jogos digitais das outras mídias e pode ajudar no processo de aprendizado. Assim jogos digitais propiciam interatividade e aprendizagem ao induzirem o usuário a experimentação, através da tentativa e erro, caracterizando o processo de aprendizado autônomo. (Albuquerque \& Fialho, 2010)

Contudo, como ressalta Santaella (2004), a interatividade varia nestes jogos: "A interatividade é uma propriedade intrínseca da comunicação digital. [...] Há os níveis mais baixos de interatividade em que a ação do usuário é meramente reativa, pois, embora suas respostas sejam imprescindíveis ao jogo, elas se dão sempre dentro de parâmetros que são as regras do jogo estabelecidas pelas variáveis do programa. Mas há também um limiar alto de interatividade, quando o programa está imbuído de complexidade, multiplicidade, não-linearidade, bi-direcionalidade, potencialidade, permutabilidade (combinatória), imprevisibilidade etc., permitindo ao usuário-interlocutor-fruidor a liberdade de participação, de intervenção, de criação (apud Silva, 2000, Santaella, $2004 \mathrm{~s} / \mathrm{p})$.
Percebe-se através dessa citação, que um jogo com alta interatividade provavelmente será bastante complexo exigindo a capacidade do usuário. Os jogos digitais, no entanto, não precisam ter alto potencial de interatividade para serem educativos. Mesmo jogos bastante simples, com baixa interatividade podem induzir o processo de assimilação cognitiva e ao raciocínio. Caso dos puzzles, que também podem ser vistos como jogos reativos por comportarem processos determinados.

Considerando esses fatores, e a partir dos questionamentos que surgem a respeito da influência dos jogos eletrônicos sobre o comportamento das crianças, torna-se oportuno investigar seus efeitos sobre a cognição infantil. Os jogos digitais constituem um campo potencial de ensino ainda pouco explorado na perspectiva da arquitetura, podendo contribuir para a divulgação do conhecimento em arquitetura patrimonial.

\section{Linguagens de programação}

O arquiteto não esta alheio à informática e à tecnologia, contudo, salvo nos projetos de pesquisa, esta se manifesta na arquitetura através dos softwares de modelagem, do design paramétrico e dos editores de imagem. Conhecimentos em linguagem de programação não são amplamente difundidos entre profissionais da área, portanto, há a possibilidade de explorar este campo de conhecimento para ampliar o horizonte de aprendizagens.

Na confecção dos jogos desta pesquisa foi utilizada a linguagem de programação Processing. Essa linguagem foi foi desenvolvida em 2001 por Casey Reas e Ben Fry, ex-alunos do MIT Média Lab. Processing tem como principal objetivo auxiliar o ensino de programação à pessoas que não estejam habituadas a programar. Nessa perspectiva a utilização dessa linguagem de código aberto (open source), contribui muito na fabricação de jogos digitais em um curto espaço de tempo. Além de possuir grande variedade de funcionalidades próprias em desenho e animação, a linguagem Processing, é um exemplar de software livre, que permite compreender o procedimento de design, fato este que não ocorre em softwares proprietários direcionados ao usuário final.

Santiago (2011), foi um dos primeiros autores a perceber o potencial da linguagem Processing no campo projetual da arquitetura. $\mathrm{O}$ autor afirma que, embora os produtos finais dessa experiência resultassem mais "abstratos" e "teóricos" do que "edificáveis", o uso dessa linguagem poderia através do processo projetual contribuir "para a reflexão sobre novas maneiras de se pensar a produção de espaços arquitetônicos, em que o papel do projetista individual dará lugar a uma atividade compartilhada por diversos indivíduos" (p.4). Isso se deve ao fato de que a linguagem Processing possui uma ampla rede de colaboradores e bibliotecas criadas por seus programadores com o objetivo de intercambiar informações e disseminar conhecimentos que possibilitam a criação de novas aplicações projetuais. Dessa forma o processo 
projetivo do programador é um processo colaborativo, que ocorre através da troca de informações, muitas vezes virtuais.

Flusser (1967) afirma que existem "jogos abertos" e "jogos fechados". Os jogos abertos seriam aqueles que possibilitariam a ampliação de seu repertório, definido como "a soma dos elementos componentes do jogo". Dessa forma diferenciam-se dos jogos fechados por terem um repertório flexível, ou seja, apresentam a possibilidade do usuário ("poeta") trazer elementos que não pertencem ao jogo ("ruídos") para dentro do repertório do jogo, ampliando-o ("poesia").

Utilizando a noção de Flusser de jogos (sistemas) abertos, Processing possibilita a modificação do projeto inicial mediante a interação do usuário com o sistema. Dessa forma é possível que não exista um produto final a ser programado, pois pode-se modificar o trabalho conforme se avança em sua confecção e com base na resposta do software, como ocorre no segundo jogo em desenvolvimento. Processing e os jogos abertos apresentam-se como exemplos de Sistemas Interativos pois permitem que o usuário possa construir seu próprio conhecimentos em lugar de assimilar conhecimentos prontos. (Santiago, 2000)

Como toda linguagem de programação, a principal característica de Processing é a possibilidade de edição livre de códigos e algorítimos para fins diverso, que altera os repertórios originais de tais linguagens, criando novas aplicações, como em um jogo aberto." (SANTIAGO, 2000, p.503-504).

Processing possui uma IDE (Integrated Development Environment) composta por um campo de escrita combinado à uma mídia visual integrada (sketchbook). A medida que o usuário escreve seus próprios códigos ou utiliza códigos de outros usuários, ele pode executá-los no sketchbook. Este renderiza os códigos transformando-os em imagens, dando ao usuário um retorno visual imediato. A manipulação e o teste dos códigos através do feedback visual, faz com que o usuário possa aprender, descobrir novos caminhos e criar novas soluções projetuais (Santiago 2011). A incorporação do sketchbook contribui para o processo de aprendizagem da linguagem, o qual se torna muito mais rápido.

Verifica-se então que a linguagem de programação pode apresentar-se como uma nova metodologia projetual, a qual também pode ser utilizada para representar e ampliar a divulgação do conhecimento em arquitetura.

\section{Resultados}

Como evidenciado, os jogos digitais são dependentes das imagens técnicas que os compõem. Portanto, os jogos desenvolvidos na pesquisa precisavam representar imageticamente as construções arquitetônicas de uma maneira fidedigna.
Os primeiros protótipos de jogos confeccionados foram quebracabeças. A escolha desse tipo de jogo deveu-se ao fato de ele ser simples e muito conhecido, sendo familiar as crianças. Como evidencia Brougère (2004), o quebra-cabeça é um jogo baseado em imagens que possui um potencial ainda pouco explorado no campo da representação em arquitetura. Esse tipo de jogo quase sempre é utilizado pra representar os exemplos mais comuns de habitat, como casas de campo, de taipa, de praia, entre outros. Através do entendimento de que o desenho pode auxiliar na compreensão de obras, elementos, espaços e lugares e assim permitir a compreensão e a reflexão sobre a paisagem e a arquitetura, verificou-se a possibilidade de sua utilização voltada para representação arquitetônica através do quebra-cabeça.

Nos quebra-cabeças desenvolvidos o desenho digital foi utilizado na composição da imagem, sendo que a linguagem de códigos possibilitou o funcionamento do jogo. Os desenhos foram feitos através de linhas e contornos sobre as fotografias das edificações estudadas, com o uso de editores de imagem. Foram aplicados testes de cores e adicionados elementos como nuvens a fim de aproximar o desenho do público infantil. Quebra-cabeças branco e preto também foram feitos para o público adulto, pois acredita-se que este dê preferência a um desenho menos infantilizado. Dessa forma o desenho pode influenciar na usabilidade do jogo, tornando-o mais atrativo ao público-alvo.

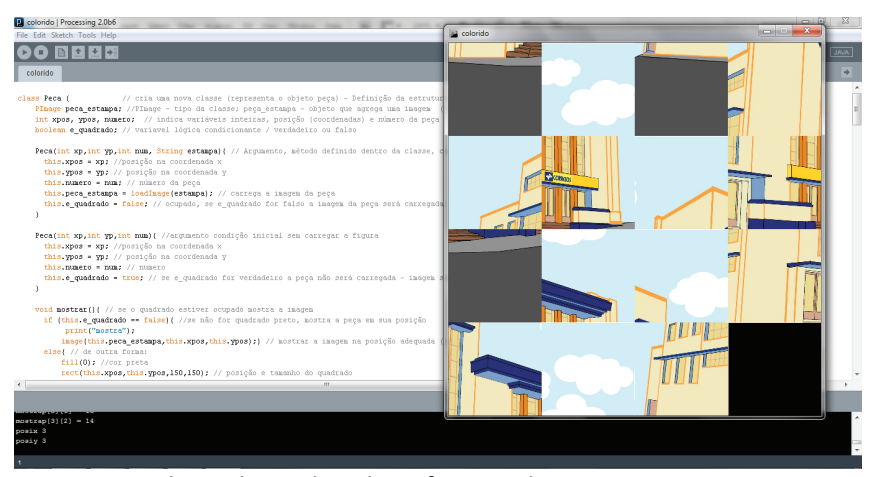
Figura 1: Quebra-cabeça digital confeccionado na IDE Processing. Fonte: Ghisolfi, 2013.

Com base nos conceitos apresentados por Flusser (1967) e Santaella (2004) este jogo pode ser visto como um jogo fechado e com pequeno grau de interatividade. Ou seja, ele apresenta interatividade, mas o usuário não pode ampliar o repertório do jogo, estando sujeito as regras específicas, que seriam a movimentação das peças para a formação da imagem e o término do jogo. Seu processo de confecção também ocorreu de forma fechada pois o código utilizado tinha um propósito específico e não houveram experimentações que levassem o jogo a propósitos diversos.

Diferentemente, no segundo jogo a linguagem de códigos atua na construção da principal imagem do jogo, um mapa digital. Esse desenho, utiliza-se dos códigos para criação de linhas de força, formando as principais ruas e quadras do centro do município de São Carlos. Dessa forma, constrói-se um mapa do município onde 
as edificações históricas são ressaltadas semelhante ao mapa do Projeto Percursos. O usuário é convidado a criar caminhos sobre o mapa, relacionando as edificações e sua localização na cidade. Assim, estimula-se o conhecimento sobre a localização das edificações no município e possibilita-se a construção de um panorama da quantidade de edificações tombadas no centro de São Carlos.

Ao contrário do ocorrido no primeiro jogo, o processo de confecção deste jogo ocorre de forma aberta. Isso acontece porque, como evidenciado, a linguagem Processing possibilita a modificação do projeto inicial mediante a interação do programador com o sistema. No caso, existia uma proposta inicial de como este jogo poderia ser desenvolvido, porém os contornos gerais dele, vão tomando forma à medida em que o software responde aos comandos do programador. O processo de confecção desse jogo ocorre portanto de forma mais interativa, à medida que desenvolve melhor a interação entre programador e interface da linguagem.

Os jogos, quebra-cabeça e mapa digital devem ser apresentados juntos ao público-alvo sendo complementares.

\section{Considerações Finais}

Jogos digitais, assim como qualquer atividade lúdica, podem proporcionar a assimilação do conhecimento de uma forma leve e descontraída, o que estimula a atenção das crianças, facilitando o aprendizado. Portanto, possuem um imenso potencial como instrumento de conhecimento. Esse potencial pode ser direcionado a divulgação do patrimônio histórico arquitetônico, aproximando-se, assim, da educação patrimonial.

Acredita-se que a educação patrimonial seja necessária para a formação de reflexões pelo aluno possibilitando a criação de uma consciência histórica que permita a valorização dos bens culturais da sua comunidade. Considera-se que o entendimento do valor patrimonial é essencial para a preservação do patrimônio arquitetônico às gerações futuras.

Conclui-se também que a aprendizagem de linguagens de programação aliada ao estudo das imagens técnicas é importante para o processo de feitura dos jogos digitais. Portanto, confirma- se com esta pesquisa a importância da integração de áreas diversas na construção do conhecimento. Dessa forma, por meio do estudo da arquitetura, do desenho digital aliado a programação, a transmissão de informações de forma lúdica e inserida no contexto da educação patrimonial torna-se possível.

\section{Agradecimentos}

Ao Núcleo de Apoio à Pesquisa em Estudos de Linguagem da Arquitetura e da Cidade (N.ELAC), ao Instituto de Arquitetura e Urbanismo de São Carlos (IAU.USP), à Pró-Reitoria de Cultura e Extensão Universitária da USP, à Fundação de Amparo à Pesquisa no Estado de São Paulo (FAPESP) e ao Conselho Nacional de Pesquisa (CNPq).

\section{Referências}

Caillois, R. (1990). Os Jogos e os Homens. Lisboa: Cotovia.

Albuquerque, R. M. de, \& Fialho, F. A. P. (2010). A interatividade e o potencial de aprendizagem através dos jogos eletrônicos. Encuentro Latinoamericano de Diseño em Palermo. Actas de Diseño n9, v. 9, 175-178.

Brougère, G. (2004). Brinquedos e Companhia. São Paulo: Cortez.

Flusser, V. (1967). Jogos. Retirado de http://www.cisc.org.br/portal/biblioteca/jogos.pdf

Flusser, V. (2008). O Universo das Imagens Técnicas. Elogio da Superficialidade. São Paulo: Annablume.

Horta, M. de L. P., Grumberg, E., \& Monteiro, A. Q. (1999). Guia Básico da Educação Patrimonial. Brasília: Instituto do Patrimônio Artístico Nacional, Museu Imperial.

Meira, A. M. (2003). Benjamin, os brinquedos e a infância contemporânea. Psicologia \& Sociologia. n.2, vol.15, 74-87. Universidade Federal do Rio Grande do Sul.

Santaella, L. (2004) Games e Comunidades Virtuais. In: Hiper> Relações Eletro/ Digitais. Porto Alegre: Santander Cultural, Retirado de: http://www.canalcontemporaneo.art.br/]tecnopoliticas/archives/00 0334.html.

Santiago, R. P. (2011) Jogos e Processos de Projeto: Diálogos Possíveis. Artigo. Faculdade de Engenharia Civil, Arquitetura e Urbanismo, Universidade Estadual de Campinas. XV Congresso SIGRADI. 